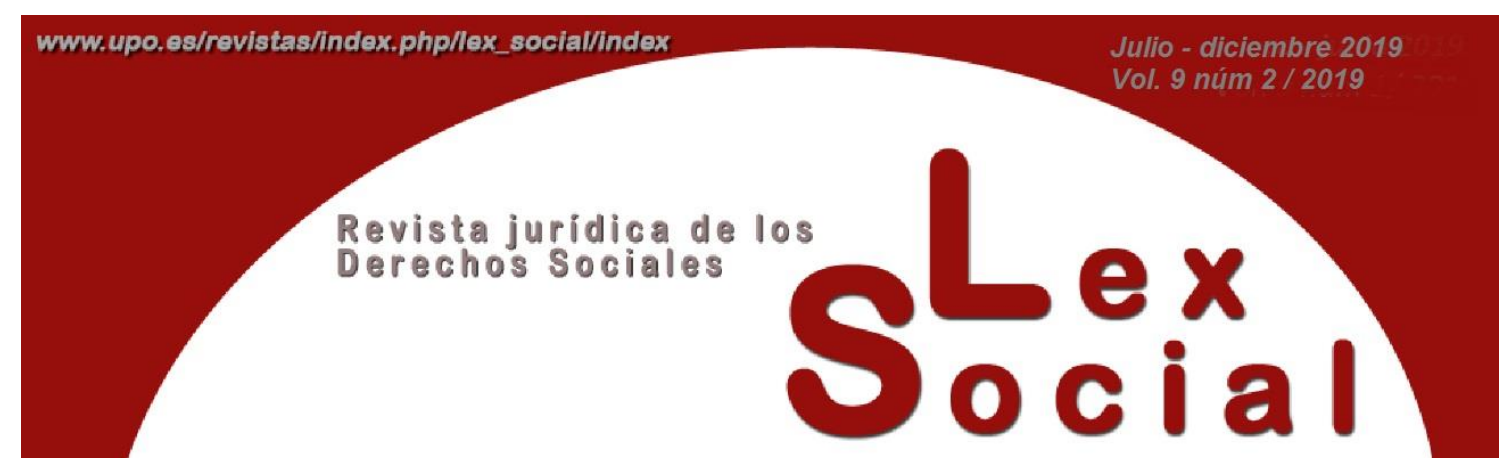

\title{
RECENSION
}

\section{Sanz Saez, C. Génesis y evolución del servicio doméstico. Comares, 2018. Colección Trabajo y Seguridad}

\author{
VANESA GARCÍA VELEZ \\ Becaría de colaboración (MEC) \\ Universidad Carlos III de Madrid.
}

En este libro de Concepción Sanz Sáez, se intentará dar explicación a los diferentes tratos jurídicos y extrajurídicos que sufren y han sufrido las trabajadoras (esencialmente mujeres, y por ello, se ha acentuado esa diferencia a lo largo de la historia) que prestan servicio doméstico.

Ya en el primer contacto que se tiene con este libro, la autora considera que lo primordial es hacer una breve cronología sobre la evolución del trabajo doméstico, pudiendo contextualizarlo mejor.

Se sitúa entonces en la época previa a la civilización romana donde reconoce que, a pesar de la falta de fuentes, ya se vivía el trabajo doméstico, pero bajo otro nombre que a día de hoy nos llega a chirriar, la "esclavitud", que dada la época en la que se vivía, por la cultura, costumbres y leyes, era más que viable.

Continúa su recorrido hacia la Edad Moderna, donde reconoce que la esclavitud fue una institución "consolidada, justificada y aceptada por la sociedad", a lo largo de las primeras páginas, se adentra en los distintos tipos de trabajo doméstico que existía por aquel entonces.

Llega entonces el principio de la regulación de esta actividad, donde encuentra su primer obstáculo para el análisis de este tipo de trabajo, y es que, asegura el autor que al tratarse de un trabajo femenino, existen menos fuentes todavía dado que la mujer no era 
reconocida socialmente en los trabajos y oficios. A pesar de esta dificultad añadida, se adentra a la regulación de dicha época, y comenzando por algunas como el Fuero de Soria año 1.135, entre otros tantos también nombrados en este libro, se nombran algunas de las muchas dificultades que se le ponía a una empleada del hogar en aquel entonces, pero, que a día de hoy no difiere mucho de las que se puede encontrar actualmente.

Menciona y analiza a continuación "el libro de las costumbres escritas de Tortosa", puesto que fue una ampliación de la regulación del servicio doméstico, y siguiendo con otras que protegían al trabajador en situaciones en las que estuviese enfermo, creándose así unas obligaciones del empleador sobre el empleado, pero el autor no quiere hacernos ver una situación solidaria, sino que quiere que veamos que esa trabajadora a la que su empleador ha cuidado y protegido mientras estaba enferma, deberá recompensar posteriormente esos días que estuvo enfermo con su mismo trabajo dejado de desempeñar por aquel entonces.

El resto de páginas de este primer punto son una serie de injusticias a mi parecer que lo único que pretendían era dejar clara la posición social que te correspondía si eras una trabajadora doméstica (y hablo en femenino porque es la mayoría de las empleadas que desarrollaban estos trabajos) y los pocos derechos que tenías, es decir, se puede hablar de una doble discriminación, por ser "esclava" y por ser mujer. De hecho, dado el poco prestigio, anota también que es a partir del siglo XVI cuando se restringe el número de criados varones, dejando a estos los oficios más nobles y a las mujeres los más deshonorosos.

Para terminar de contextualizar esta época, se habla también de los tipos de tarea que podía realizar cada criada y a según qué clase social se sirviese. La autora deja su punto de vista muy claro con su forma de hablar sobre el pasado de este tipo de trabajo, intenta mostrar al lector los pocos derechos que se tenía en aquel entonces, dando incluso el dato de que los padres o tutores de las niñas menores de edad eran los representantes a la hora de redactar un contrato de criada.

Su siguiente título a tratar es la "institucionalización de los servicios de prestación a través de las Casas de Madres y Padres de Mozas", y es que Sanz pretende que veamos cómo se pretende a partir del siglo XVII, con la creación de estas oficinas de colocación, la vigilancia, orientación y cierta regulación o protección a las criadas, queriendo evitar los excesos de "mozas de servicio". Pero, nuevamente quiere mostrarnos la crueldad que se seguía viviendo si eras una moza de servicio, y es que si no se te encontraba trabajo en ocho días, eran expulsadas y declaradas vagabundas, además, aunque consiguieses trabajo, no tenías derecho a reclamar un solo día libre semanal de descanso, ni siquiera obtener un nuevo empleo si no era con una certificación de su anterior "amo". 
A continuación, la autora quiere centrarse en la cobertura prestacional del servicio doméstico, hablando de la aparición del Montepío para hablar del inicio de las mismas. Muy destacable es en este punto que se tenía en cuenta exactamente qué tipo de trabajadora doméstica eras, y es que una criada, tenía mejores condiciones que un criado de labor pero a su vez tenía mucha mayor dependencia del amo al recibir alojamiento y manutención de su parte. La contextualización constante en la que te provoca a sumergirte el autor a lo largo de sus líneas te causa sentimiento de angustia hacia esas trabajadoras totalmente desprotegidas puesto que, como era previsible, su cobertura prestacional en el siglo XVIII era ridícula.

Nos adentramos entonces en el segundo capítulo de este libro, donde encontramos ya la etapa de unificación de leyes y momento en el que se nombra la Ley de Enjuiciamiento Civil de febrero de 1881, donde, da la primera definición del servicio doméstico en su artículo 660, aunque no fue hasta 1889 cuando llega la regulación concreta del "criado doméstico". Continúa nombrando ciertos cambios y sobretodo destaca, dando un aliento de esperanza al lector, la eliminación del contrato de servidumbre prohibiendo el arrendamiento de servicios vitalicio que se venía dando hasta dicho momento. También entra en juego otros beneficios hacia el criado doméstico con el Código Civil en el 89, como ejemplo destacable el autor nos nombra la indemnización de salario devengado y el de 15 días más en caso de que el amo decida rescindir el contrato de trabajo con este antes de la fecha indicada en el mismo.

Se dedica en el siguiente título a la primera ley de accidentes de trabajo, siendo esta la ley de 30 de enero de 1900, y la cual, en consonancia con la primera parte del libro, no era de aplicación a los empleados domésticos, que, pese a las revisiones que se hicieron a dicha ley, continuaba excluyéndolos hasta más de la ley de accidentes de trabajo de 1932. Continuando con otras desigualdades que sufrían estos empleados como la exclusión en el descanso dominical. Se puede ver un contraste entre el pequeño hilo de esperanza que estaba dando al lector en una página con la bofetada de realidad que recibimos justo después, intenta con ello mostrarnos que se intentaba dar pequeñas migas de pan a este colectivo para hacerles ver que sí podían disfrutar de protección pero sin embargo, siguen teniendo un lugar distinto al resto de trabajadores a los que sí se les extendió poco a poco esta ley de accidentes.

Los siguientes títulos hablan de distintas leyes que empiezan a reconocer más derechos a algunos tipos de "criados" pero siempre excluyendo a aquellos dedicados al servicio personal del amo o patrono y de su familia, pareciendo mostrar lo costoso que es reconocer este tipo de trabajo como cualquier otro que pueda desempeñarse a pesar de su similitud con ellos, y es que, existe un empleado o empleada, un empleador y un servicio prestado a cambio de un salario (del cual claramente se ha abusado a lo largo de la historia por ofrecerles un hogar y una manutención a dicho empleado, punto que intenta dejar muy marcado el autor). 
Es realmente interesante el análisis que hace también a la exclusión que sufría el trabajo doméstico de los seguros sociales en las siguientes páginas, para ello nombra y dicta algunas de las conclusiones de la Conferencia de Seguros Sociales de octubre de 1917 en Madrid. Se centra concretamente en la prestación por maternidad, del cual, quedaban excluidas aquellas que trabajen en servicio exclusivamente doméstico aún en el Real decreto de enero de 1930.

Hace también referencia a los distintos tipos de empleo doméstico que existía y cómo se fueron tratando a cada empleado de distinta manera según la función que desempeñase, es decir, explica los diferentes derechos que se le reconocían según las funciones que tuviera en su puesto (cocineros, chófer, cuidados personales o de limpieza... etc).

Tras la lectura de este segundo capítulo, queda claro que lo que pretende hacernos entender la autora del libro es lo excluidas que se tenía a aquellas mujeres que se dedicaban al servicio doméstico del resto de trabajos, con la consecuencia de tener una protección mínima y ridícula.

Nos encontramos ahora con el tercer capítulo, el cual se abre mencionando la Ley Republicana de Contrato de Trabajo del 21 de noviembre de 1931, relevante para este análisis evolutivo por ser la primera ley que reconoce el carácter laboral en los servicios prestados en un domicilio para la realización de tareas domésticas. Sin embargo, continúa exponiendo diferencias y exclusiones a este tipo de trabajadoras, como es la exclusión que sufrían (junto a los funcionarios) respecto del seguro contra el paro que crea la Caja Nacional en 1931. Menciona además, que hasta dicho momento no se había podido reconocer como trabajo no como un menosprecio del mismo, sino porque se consideraba que el empleador no contrataba bajo un ánimo de lucro propio, sino que, por el contrario, sólo lo contrataba para hacer unas tareas del día a día y no para "hacer dinero". Queda clara la posición contraria de la autora ante esta explicación, tomándola simplemente como una excusa que han querido dar ante una total exclusión que es, a mi parecer, errónea. Además, al incluir el servicio doméstico en la Ley de contrato de trabajo desde el inicio teniendo en cuenta las particularidades de tal puesto, dio lugar a que la aplicación de este en legislación general fuese imposible.

A pesar de ello, con esta incorporación del servicio doméstico a la Ley de Contratos de Trabajo, la protección hacia ellos se ve mejorada, mencionando así en sus artículos 39, por ejemplo, el deber del patrono de proporcionar alojamiento y comidas "adecuadas", o en el núm. 40 la obligación de dar auxilios médicos si enfermaban. Pero, se denuncia en este libro que, a pesar de ciertas mejoras, no existió equiparación en el terreno de la protección social, respecto de seguros como invalidez, muerte, paro o enfermedad. Dedica entonces las siguientes páginas a importantes pasos que se dieron con la Ley de 4 de julio de 1932 respecto de la protección social en el tema de accidentes concretamente. Se ordena al INP preparar proyectos de seguro de enfermedad, invalidez, muerte y estudios de unificación de los Seguros sociales de invalidez, vejez, ISSN: $2174-6419$

Lex Social, vol. 9, núm. 2 (2019)

\section{(cc) EY-NC-SA}


maternidad y muerte, incluyendo en la Base segunda al servicio doméstico como beneficiarios de dichos seguros. Pero, a pesar de este gran avance hacia la equidad, en 1934, vuelven a sufrir la exclusión de la ampliación del seguro de maternidad ateniéndose a una disposición transitoria del 29. Se deja constancia de que cada paso adelante que daba este colectivo, la ley le obligaba a dar dos hacia atrás, creando sentimiento de impotencia y frustración constantemente.

Después, en el capítulo cuarto entra a analizar la etapa de la dictadura y cómo esto afectó al empleo doméstico. Ya en su primera página reconoce lo difícil que le resultaba a una mujer la época franquista, cuanto más lo sería para aquellas que quisieran trabajar y tener igualdad. Las consecuencias de la guerra civil y la dictadura provocaron la reclusión de la mujer en el hogar para tan sólo atender a sus responsabilidades familiares, casi impidiéndola trabajar fuera de su propio hogar. Se dedica a analizar el derecho a la asistencia en el embarazo y parto durante esta etapa, y es que, en 1942 se reconoció el derecho a dicha asistencia a las trabajadoras afiliadas al régimen de subsidios familiares que no fueran afiliadas al de maternidad por superar un límite de retribución, reconociendo así protección a las trabajadoras por cuenta ajena pero excluyendo, nuevamente, a las trabajadoras del servicio doméstico, puesto que estaban excluidas del régimen de subsidios familiares. Además se cubrió a esposas de asegurados siempre que estas no trabajasen fuera de su propia casa. Dejaban entonces fuera de esta asistencia a las trabajadoras domésticas internad solteras, que en aquel momento eran la mayoría de este colectivo. Entra a analizar los requisitos que requería una mujer trabajadora para conseguir protección en esos tiempos.

Dedica la mayor parte del capítulo quinto a los cambios de los contratos de la mujer y de la mujer casada, para poner en situación al lector de todas aquellas exclusiones y distintos tratos que debía soportar la mujer por el simple hecho de ser mujer. Se puede observar cómo explica de forma muy minuciosa todo tipo de cambios que sufría la empleada doméstica tanto en contratos como en cuanto a seguros de los que podía ser beneficiaria, además, analiza la evolución respetando cautelosamente su orden cronológico y situando siempre al lector en el año al que se refiere en cada momento. Sigue los capítulos con las diferencias de género que existían y cómo esto repercutía en un trabajo esencialmente femenino y además, desprestigiado, provocando un importante desaliño de la regulación del mismo.

Continuamos con el capítulo séptimo, dedicado a la regulación de prestaciones que sufre este sector, llevando al lector de lo más general (para contextualizarle correctamente con leyes como la Ley de Bases de la Seguridad Social) hasta lo más concreto, haciendo hincapié en títulos como el reconocimiento de los derechos sociales a las mujeres, conseguidos en su gran mayoría por una falsa condición de debilidad de la mujer que las justifica como beneficiarias de pensiones tales como la de muerte y 
supervivencia tras la muerte del hombre, tratándolas como personas indefensas sin una figura masculina al lado que la mantenga y proteja.

Finaliza este libro dedicándolo a la Ley de Relaciones Laborales de 1976 por considerarlo "la cota más alta de derechos laborales individuales que se había alcanzado", y que por primera vez se incluye el término relaciones laborales especiales, ofreciendo novedades legislativas, como es laboralizar relaciones que se situaban fuera del derecho del trabajo, como el servicio de hogares familiares, y dejando de ser el trabajo doméstico una relación civil de arrendamiento para ser una relación laboral especial, liberando a las mujeres de la necesidad de autorización marital para la contratación. También se decide a analizar y explorar los cambios que supuso la Ley de 8/1980 de 10 de marzo del Estatuto de los Trabajadores, puesto que abre camino a la flexibilización del mercado de trabajo puesto que institucionaliza la contratación temporal por Ley Orgánica.

Utiliza las últimas páginas para hacer unas reflexiones de lo más interesantes, y que nos llevan a pensar cómo la sociedad ha obviado el trabajo doméstico de una forma tan descarada y cómo hemos permitido esta desigualdad durante tantos años. Este libro sirve como ayuda para comprender lo costoso que ha sido y es conseguir la igualdad, porque la historia nos ayuda a aprender de los errores ya cometidos en el pasado y nos impulsa a corregir los que aún continúan siendo visibles a día de hoy.

Mi reflexión final es que la cultura de España ha sido machista y patriarcal y ello ha dejado resquicios en la actualidad que debemos erradicar lo antes posible, y esa erradicación se comenzará a hacer sólo cuando todos seamos conscientes de ello. Para abrir los ojos a la parte de la sociedad que aún no piensa en la igualdad de género total, se necesita comenzar por la educación de los niños, pues ellos son el futuro y el inicio del cambio a una sociedad más equitativa y mejor. 